\title{
Response to cash outs for work place parking and work place parking charges
}

\author{
Paul Watters, Margaret O’Mahony \& Brian Caulfield
}

Department of Civil, Structural \& Environmental Engineering, Centre for Transport Research, Trinity College Dublin, Dublin 2, Ireland

\begin{abstract}
Free work place parking has long been considered to have a strong influence on whether or not individuals use their car for their trips to work. A survey of local authority employees was conducted to examine their potential responses to the removal of free work place parking spaces, how they would respond to parking cash-out policies and to work place parking charges, and finally their responses to specific values of cash out payments. It was found that as age increases individuals are less likely to accept any form of cash out. When individuals have one or more cars available they are more likely to opt for a cash out scheme. Females are more likely to opt for the various cash out schemes than males. The results seem to suggest that if an individual has a higher income it does not necessarily mean they will opt to keep their space.
\end{abstract}

\section{Introduction}

The availability of free work place parking is generally considered to have a significant influence on car use for work trips. Managing work place parking has therefore been examined as a demand management measure to see what its potential is for reducing car trips to the work place. One of the strategies considered for this has been the cash out policy. Under a parking 'cash-out' scheme, an employer who offers an employee a parking subsidy must also offer that employee the option to choose the cash equivalent of that parking subsidy instead. The objective of this paper is to evaluate how individuals would respond if indeed a cash equivalent was on offer in the form of a cashout. Different levels of cash out are offered to the individuals and the results of their responses are included later in the paper. In addition, the research examines the response to the removal of free work place parking and the imposition of work place parking charges.

\section{Background}

A general overview of the transport demand in Dublin, the city in which the survey discussed later was completed, is presented in this section. The commuting footprint for the Greater Dublin Area (GDA) is getting close to one third the area of Ireland. This is due to rapid economic and population growth with a large number of commuters travelling significant distances to work. Regional rail travel has not kept pace with the demand and therefore there is an over-reliance on the car as a mode of transport resulting in traffic congestion. The problems have been exacerbated by inflated house prices in the Dublin area to the extent that people born in Dublin in many cases cannot afford to buy houses there and have moved to the limit of the commuting footprint for more affordable housing. 
Over $80 \%$ of State sponsored bodies are located in Dublin, which also is the location for about $70 \%$ of theheadquarters of the major public and private companies and co-operatives. Over $57 \%$ of the parking spaces available in Dublin in 2002 were private office parking (this excludes parking within the Financial Services Centre, another significant attractor of car based work trips) (Dublin City Business Association, 2002). Moreover, 60\% of this office car parking was Government parking. At the end of 2001 there were over 1.38 million private cars in Ireland, compared with less than 0.8 million in 1990 (CSO, 2003a-c). Car ownership rates in the GDA are steadily increasing towards the European average and by 2016 are expected to be 48 cars per 100 head of population. An international comparison of car usage reveals that Ireland has the highest levels of car usage in the EU with the average car in Ireland travelling $24,400 \mathrm{~km} /$ annum. This is $70 \%$ higher than France and Germany and $50 \%$ higher than Britain. Furthermore, and more surprising, is that this figure is $30 \%$ higher than the USA (Banister and Berechman, 2000).

Over half (54.1\%) of workers in Ireland drive to work, with over three-quarters of them not carrying any passengers (CSO, 2000). A further $8.6 \%$ get a lift to work in a car or van. Over $68 \%$ of car/van drivers from Dublin usually park their car in work (not designated) with a further $10 \%$ having a designated parking space at work. More importantly, only 3.6\% of drivers in Dublin pay for parking when at work (CSO, 2000). The provision of free or cheap parking at work by employers is not treated as a benefit-in-kind taxation item in Ireland. However, Irish employees are offered tax and national insurance benefits for commuter travel, which can amount to $48 \%$ of their travel costs on public transport. Under this TaxSaver Commuter Ticket Scheme, tax and national insurance liability is deducted from the cost of the travel ticket. It is against this background that the work place parking objectives of this paper are set.

\section{Work place parking}

This section examines the research covered to date on work place parking. A large body of work has been completed but it is the subtleties of the findings that are the most interesting, the most noticeable of which are presented here. Shoup (1997a) has carried out a considerable amount of work in the area of work place parking. He presented the results of eight firms studied complying with California's parking cash out requirement. He found that for the 1694 employees of the eight firms the number of solo drivers to work fell from $76 \%$ to $63 \%$ after cashing out. The number of car poolers increased from $14 \%$ to $23 \%$, the number of transit riders from $6 \%$ to $9 \%$, the number walking increased from $2 \%$ to $3 \%$ and those cycling increased from $0.8 \%$ to $0.9 \%$. Low-priced or free employer-provided parking at the workplace may discourage use of public transport (Merriman, 1998).

There are numerous ways to address workplace parking. Parking charges can be applied (or increased), the number of parking spaces can be reduced or some reserved for car sharers, a benefitin-kind tax can be applied to the provision of spaces, a workplace parking levy can be applied by the local authorities, or employees can even be offered a cash-value in lieu of a parking space, typically referred to as a cash out. 
There have been a number of recent studies which addressed the business response to the implementation of workplace parking levies (Gerrard et al., 2001; MVA Ltd. and WS Atkins Ltd., 1999; Wang and Sharples, 1999). Most employers stated that they would pay the levy rather than reduce the number of parking spaces or pass on the cost to their employees. Many employers are concerned that parking measures devalue the fringe benefits of their employees, and thus will compensate for any effects of the measures on their employees (Van der Mede and Visser, 1999). Hence, the effectiveness of a workplace parking levy will be severely affected by whether an employer passes on the levy to employees or reduces the number of parking spaces available (Van Vuren and Johnson, 2000). Furthermore, an employer may not be willing to introduce parking measures that will discourage employees from travelling to work or which force them to use less convenient modes of travel to work which could have repercussions for punctuality and attendance (Simpson, 2001).

In the PATS project (Link et al., 2000) just over 30\% of respondents agreed in principle with the idea of a work place parking levy (WPL). Based on an annual fee of stg6£3000 across the extended Central London Area, 47\% of people surveyed thought that a WPL would be a 'good thing', compared to $40 \%$ who thought it would be a 'bad thing' for London (ROCOL, 2000). Only 13\% of employees thought it would be a good thing for London. Furthermore, approximately half the employees surveyed believed that a WPL would be of no benefit for London.

A number of studies have investigated the impact of free/subsidised parking on the mode choice decisions of employees. Taking away free parking at the place of employment can reduce the number of cars driven by solo drivers by 40-44\% (Willson, 1992; Shoup and Willson, 1992). Furthermore, Willson (1992) found that 25-34\% fewer automobiles were driven to work when workers had to pay to park, as compared to when they parked free. Shoup (2002) states that free parking is the unstudied link between transportation and land use, urban planners make serious mistakes in dealing with parking and that these mistakes gravely distort the markets for both transportation and land.

Limiting the number of spaces or charging for the use of car parking spaces is widely recognised as an effective tool in any travel demand management strategy. A better approach maybe to 'bribe' drivers to use other modes of travel to work (Enoch, 2002) by introducing parking 'cashout'. Under a parking 'cash-out' scheme, an employer who offers an employee a parking subsidy must also offer that employee the option to choose the cash equivalent of that parking subsidy instead (Shoup and Willson, 1992). Presenting an employee with a cash alternative to free parking indicates that there is an opportunity cost associated with parking (Shoup and Willson, 1992).

Shoup (1997b) compared the cost of providing free parking to the price commuters paid to drive to work in an attempt to investigate the extent to which free parking offered by employers subsidized car use. He found that the subsidy for free parking at work was triple the vehicle operating costs of driving to work. Furthermore, he found that a driver's variable costs of car commuting without free parking was quadruple this cost with free parking at work. A similar calculation for Dublin (calculated by the authors of this paper) found that the subsidy for free parking at work in Dublin is almost 1.5 times the vehicle operating costs for driving to work. Furthermore, the driver's variable cost of car commuting without free parking is 2.4 times this cost with free parking. 
A number of studies have examined the impact of work place parking charges. Farrell and O'Mahony (2005) looked at the reaction to a h5 per day charge in Dublin, Ison and Wall (2000) assessed the attitudes to aWPL in the UK while Hess (2001) looked at a range of different charges from $\$ 1$ to $\$ 6$ or more per day in Portland, Oregan. According to United States Environmental Protection Agency (USEPA) (2001) parking cash-out works best for employers who lease their parking spaces from their building. The employer simply leases fewer or no parking spaces from the vendor and passes the money on to itsemployees.

\section{The survey}

The main aim of this study was to investigate employees' attitudes and potential travel behaviour responses to measures to deal with parking in the workplace and, in particular, their responses to a cash out policy and different cash out scenarios. A web-based questionnaire was used to elicit responses from employees of a local authority based in Dublin's city centre. The originality of the work lies in the investigation of a relatively innovative policy measure, work place parking, by an equally novel method of survey by means of the internet. The software used is surveymonkey and according to Gordon (2002) is a serious and excellent survey and evaluation tool.

Some of the benefits of web-based surveys include easy tailoring of messages, immediate access to the data, more accurate data, and reduced survey costs (Magee et al., 2001). Furthermore, web-based surveys can be more user friendly, offer more simple directions, greater range and more interesting layouts for questions (Klassen and Jacobs, 2001). Other advantages put forward by Wright (2005)include access to unique populations, saving researcher time, enables researchers to do preliminary analyses quickly and going back to the responders quickly should particular issues arise and significantly reduced costs. Wright (2005) finds the disadvantages to include sampling issues, particularly relating to self-reporting with no opportunity to check the validity of for example demographic or characteristic information. Other problems relate to the fact that some people are 'regular' responders to this type of survey, self-selection bias and internet access limitations. However, a major factor for consideration is the potential sampling bias associated with web surveys (Hayslett and Wildemuth, 2004), that is, not everyone has access to the internet. Web-based surveys offer a number of powerful advantages over traditional survey modes (Joinson and Reips, 2005) such as those suggested by Wright (2005) above. However, they do present some problems but measurement error and non-response error should be decreased if the survey is constructed in a respondent friendly manner (Dillman et al., 1998).

The web-based survey used falls in the category of stated preference. For this type of situation, where we examine a policy not currently in existence, stated preference is very useful because revealed preference only offers the opportunity to examine existing alternatives (Louviere et al., 2005). They also find that stated preference surveys can capture a wider and broader array of preference-driven behaviours than revealed preference. On the other hand, it is recognised that stated preference data are hypothetical and experience difficulty taking into account certain types of real market constraints (Louviere et al., 2005). Another issue is the possible 'halo effect' where the respondents in this survey may have responded more positively to the scenarios than they might actually do in practice. It is difficult to determine if this effect is present in the data. It is also difficult to say how the results 
might be reflected in reality. One possible way of validating this would be to conduct a pilot survey followed by a large scale trial in a particular work place setting.

\section{Survey results}

\subsection{Summary results}

The web-link to the questionnaire was emailed to 2137 employees. A total of 473 employees submitted the questionnaire, however, not all of the surveys were fully complete. Fifty-eight per cent of respondents revealed that they regularly drove to work (51\% alone and $7 \%$ taking passengers). Of the respondents, $16 \%$ stated that they regularly took the bus and $7 \%$ regularly go to work using rail based modes (commuter rail, heavy rail, light rail transit). A total of $15 \%$ either walk or cycle regularly. The average distance travelled to work was $15.4 \mathrm{~km}$ (SD: 19.7) and average travel time is 43.6 mins (SD: 31.5).

\subsection{Characteristics of respondents}

Of the 411 who answered the socio-economic questions, 231 (56.2\%) were male and 180 (43.8\%) were female. Thirty-two per cent (132) were in the 17-25 age group, almost $28 \%$ (115) in the 36-45 age group, close to $23 \%$ (93) in the $26-35$ age group and $7.6 \%$ (31) in the $46-55$ age group. In terms of job status, over 33\% (136) were professional, 32.6\% (134) were clerical, 15\% (62) were middle management, $9.5 \%$ (39) were technical and 6\% (25) were senior management. Looking at income levels, close to $25 \%$ were in the salary range $€ 30,000-40,000,20.4 \%$ (84) in the $€ 20,000-30,000$ range, $16.5 \%(68)$ in the range $€ 50,000-60,000$, almost $13 \%(53)$ in the $€ 40,000-50,000$ range, $11.6 \%$ (48) in the range $€ 10,000-20,000$ and the remainder in the ranges below this and above $€ 60,000$. Of the 409 individuals who answered the question on car ownership, 46.7\% (191) own one car in their household, $41.1 \%$ (168) own 2 cars and 6.1\% (25) own 3 or more cars with a similar number not owning a car at all.

\subsection{Availability of parking and mode choice}

The most common reason for choosing to drive to work was that the car was needed at work, followed by its convenience over other options and then by its comfort over other options. Notably, convenient and/or cheap parking at work was the fifth-most common reason for travelling to work by car. In the case of those individuals using public transport for their journey to work, the most common reason suggested was that it was quicker than other options. This was followed by convenience and followed again by cheaper than other options. Although parking issues were not the main reason why particular modes of travel were chosen, they were among the most common reasons. When asked how many days did they drive their car for work purposes in the previous week, over 24\% (114) said they used it on 1-2 days, over 25\% (118) used it on more than 3 days and 50\% (233) said they did not use their car for work purposes during the previous week.

Over 51\% (244) have a staff-parking permit with over 48\% (231) not in possession of one and the remainder did not answer the question. Seventy-six per cent (282) park in spaces at their work place 
but these car parking spaces arenot designated. A much smaller percentage, $7.5 \%$ (28), park in designated parking spaces. 4.3\% (16) park in a designated space in another car park, 11.6\% (43) park on-street and $3.2 \%$ (12) park in multi-storey car parks. In relation to the availability of car parking spaces, the findings from the participants are presented in Table 1. Relatively high percentages have never found a problem finding a car parking space $(52 \%)$ with much smaller numbers having varying degrees of difficulties. In total, $81 \%$ have never changed to another transport mode due to difficulties finding a car parking space and $62 \%$ have never changed their departure time from home due to car parking difficulties.

\subsection{Behavioural response to a $€ 5$ a day charge to park at work}

Respondents were asked what they would do if free parking was not available and it cost $€ 5$ per day to park at work. They could choose up to three options from a list of 11 and 403 individuals answered the question. Continuing to drive to work and park somewhere else for free $(31.5 \%, 127)$, travel some days by public transport $(22.8 \%, 92)$, continue to drive to work and pay the extra $(22.3 \%$, $90)$ and use public transport every day $(21.8 \%, 88)$ were the four most favoured responses. Over $10 \%$ stated that they would look for another job if parking at work cost $€ 5$ per day. Just over $14 \%$ (56) of respondents stated they would be prepared to pay for parking while at work and $72 \%$ said they would not. Although the next question was directed to those who would be prepared to pay for parking at work (56), some 131 answered the question. Of them, almost $17 \%$ (22) would prefer to pay an annual parking fee, $27.5 \%$ (36) a monthly fee and $36.6 \%(48)$ a daily parking fee. There were 90 responses to a question asking how much they would be prepared to pay for parking at work. The range for an annual fee was between $€ 100$ and $€ 2000$ per year; 6 indicated they would be prepared to pay $€ 100$ and a further 6 suggested $€ 200$. At the higher levels, only 6 individuals in total were prepared to pay between $€ 1000$ and $€ 2000$. For the monthly fee, the range suggested was $€ 5-€ 250$ with only 2 out of 37 prepared to pay over $€ 100$. Most of the respondents (25) said they would be only prepared to pay less than $€ 50$ per month. Finally, when asked how much they would be prepared to pay for a daily rate, the range was between $€ 1$ and $€ 27$ with 45 out of 50 prepared to pay less than $€ 5$ per day.

\subsection{Parking cash-out}

Respondents were given details of how a parking cashout scheme would operate. After the explanation was presented, they were first asked to choose which of a number of commuting options they would choose if their employer offered a parking cash-out. Of the 388 respondents who answered the question, just over 61\% (238) said they would keep their free parking space, over 13\% (51) would give up their parking space and cycle or walk to work and receive the value of the parking space in taxable income, just over 10\% (39) would give up their parking space and receive a tax-free public transport ticket with the remainder choosing between joining a car pool $(2.3 \%, 9)$, giving up their space, parking elsewhere and receiving the value of the parking space in taxable income $(5.7 \%$, $22)$ and other $(7.5 \%, 29)$. 
Table 1

Over the last year of travelling to work, how often has the following happened?

\begin{tabular}{|c|c|c|c|c|c|}
\hline & Very often & Fairly often & Sometimes & Almost never & Never \\
\hline $\begin{array}{l}\text { I have driven to work and have been unable to find a } \\
\text { parking space }\end{array}$ & $3 \%(11)$ & $4 \%(17)$ & $19 \%(74)$ & $22 \%(88)$ & $\$ 2 \%(202)$ \\
\hline $\begin{array}{l}\text { I have changed my mode of travel due to difficulties finding } \\
\text { a parking space }\end{array}$ & $S \%(15)$ & $2 \%(7)$ & $4 \%(13)$ & $8 \%(24)$ & $81 \%$ (255) \\
\hline $\begin{array}{l}\text { I have changed my departure time from home to work due } \\
\text { to difficulties finding a parking space }\end{array}$ & $12 \%(39)$ & $7 \%(25)$ & $13 \%(43)$ & $6 \%(20)$ & $62 \%(210)$ \\
\hline
\end{tabular}

The next part of the questionnaire involved offering a number of scenarios centred around the cash out proposals. This is similar to the set of scenarios presented in Farrell and O'Mahony (2005) on another Dublin sample but addresses a weakness in that work by assigning actual values to the amount of the cash-out offered. This enables a much more definitive set of scenarios to be presented to the respondents and reduces the problems of ambiguity with their choices.

It was suggested in the questionnaire that should a cashout scheme be implemented, there were a number of possible ways of giving up the parking space. The first option was to give up the space permanently and receive a substantial one-off cash payment but it was made clear they could never again park at the workplace. The second option was to give up the space on an annual basis for $€ 1300$ for the year but if they chose this option they could not change their mind and choose to park again at the work place until the following year. The third option was to give up the parking space on a monthly basis and receive $€ 100$ for the month but they could not choose to park again until the following month. The final option was to give up the space on a daily basis and receive $\mathrm{h} 4$ for the day and have the option of choosing on each day whether you would like to park or take the cash value. The preferences given to each option are presented in Fig. 1. As expected, giving up the space permanently is the least popular with $75 \%$ of the group giving it preference 4 (least favoured). In the case of giving up the space for a year and receiving the relevant payment, over $30 \%$ give this a preference of 1 or 2 indicating some acceptance of it as a demand management strategy. To put this in context, in the case of reducing congestion in urban areas, relatively small reductions in overall car trips can make significant improvements and so this result is encouraging. However, the subtlety of this point in relation to the absolute benefits of this policy considered in isolation is worth noting i.e. if congestion is reduced, fewer individuals may be willing to give up their car parking space. This is a difficulty with many demand management strategies but perhaps if this strategy was used in conjunction with other strategies as part of an integrated transport policy programme, the effects may not induce a negative overall impact. In the case of giving up the space each week, almost $80 \%$ give this either a preference of 1 or 2 . Finally, in the case of giving up the space for a day, while one would expect this to receive the highest number of first and second preferences combined, what is interesting is the number of individuals giving it a third or fourth preference-over $30 \%$.

A number of variables were tested for significance such as 'mode used', 'distance to work' and 'job status'. However, only 'gender', 'age', 'income' and 'car availability' were found to be significant and these results are presented in Table 2. Firstly, it is interesting to note that the results for all types of 'cash out' are similar in trend, and secondly that there does not seem to be one 'cash out' mechanism 
that is more effective than others. The results also demonstrate that the only negative relationship is that between 'age' and 'cash out', indicating that as 'age' increases individuals are less likely to accept any form of 'cash out'. The figures for 'car available' indicate that when individuals have one or more cars available they are more likely to opt for a 'cash out' scheme. Income also demonstrates similar characteristics to 'car available', in that positive coefficients were found which demonstrate that higher incomes in this case do not mean that individuals will opt to keep their space. The analysis of gender suggests that females are more likely to opt for the various 'cash out' schemes than males.

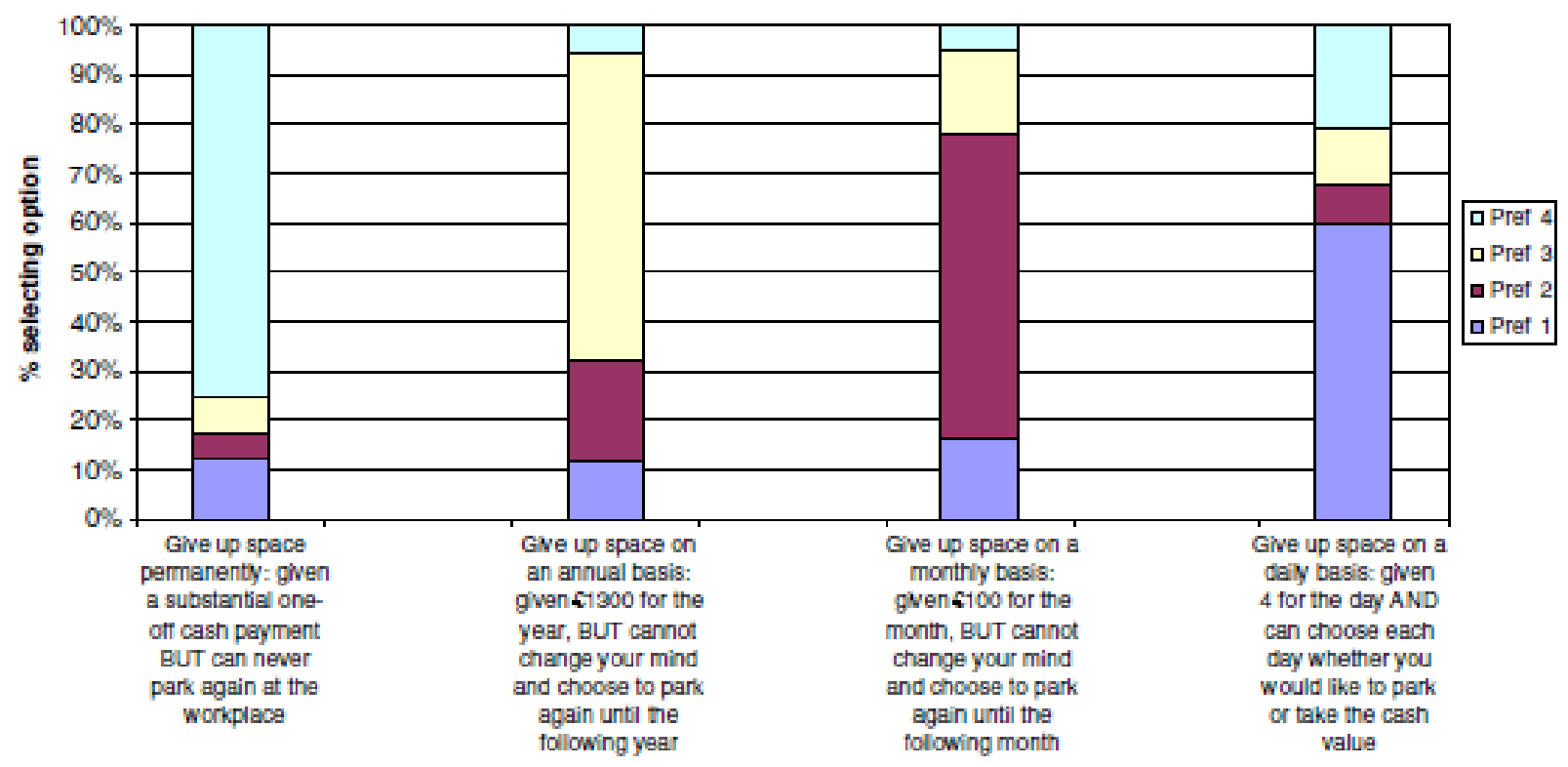

Fig. 1. Preferences for different cash out schemes. 
Table 2

Parking cash-out options

\begin{tabular}{lcc}
\hline Parking cash out (giving up space for) & Coeff & $t$-Ratio \\
\hline Substantial one-off cash payment & & \\
Gender & 0.389 & 2.1235 \\
Age & -0.439 & -2.0765 \\
Income & 0.457 & 13.793 \\
Car available & 0.585 & 5.494 \\
Annul payment of $\in$ / 300 & & \\
Gender & 0.387 & 2.120 \\
Age & -0.460 & -2.179 \\
Income & 0.489 & 14.803 \\
Car available & 0.5746 & 5.409 \\
Monthly payment of $\in$ I00 & & \\
Gender & 0.379 & 2.091 \\
Age & -0.451 & -2.150 \\
Income & 0.489 & 14.909 \\
Car available & 0.573 & 5.434 \\
Daily payment of $\in 4$ & & \\
Gender & & 1.956 \\
Age & 0.348 & 5.5 \\
Income & -0.393 & -1.906 \\
Car available & 0.457 & 14.159 \\
\hline
\end{tabular}

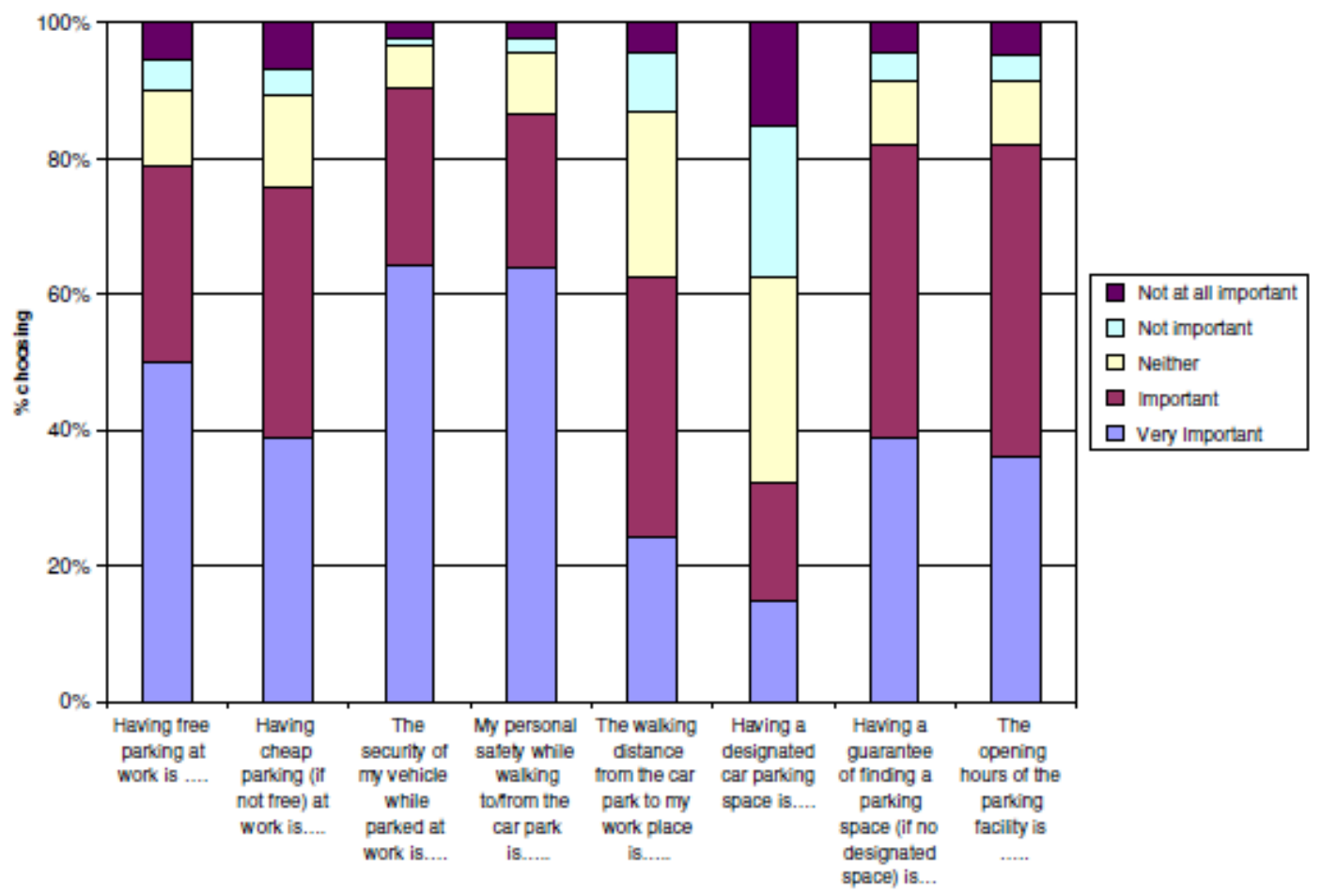

Fig. 2. Attitudinal responses to work place parking issues. 


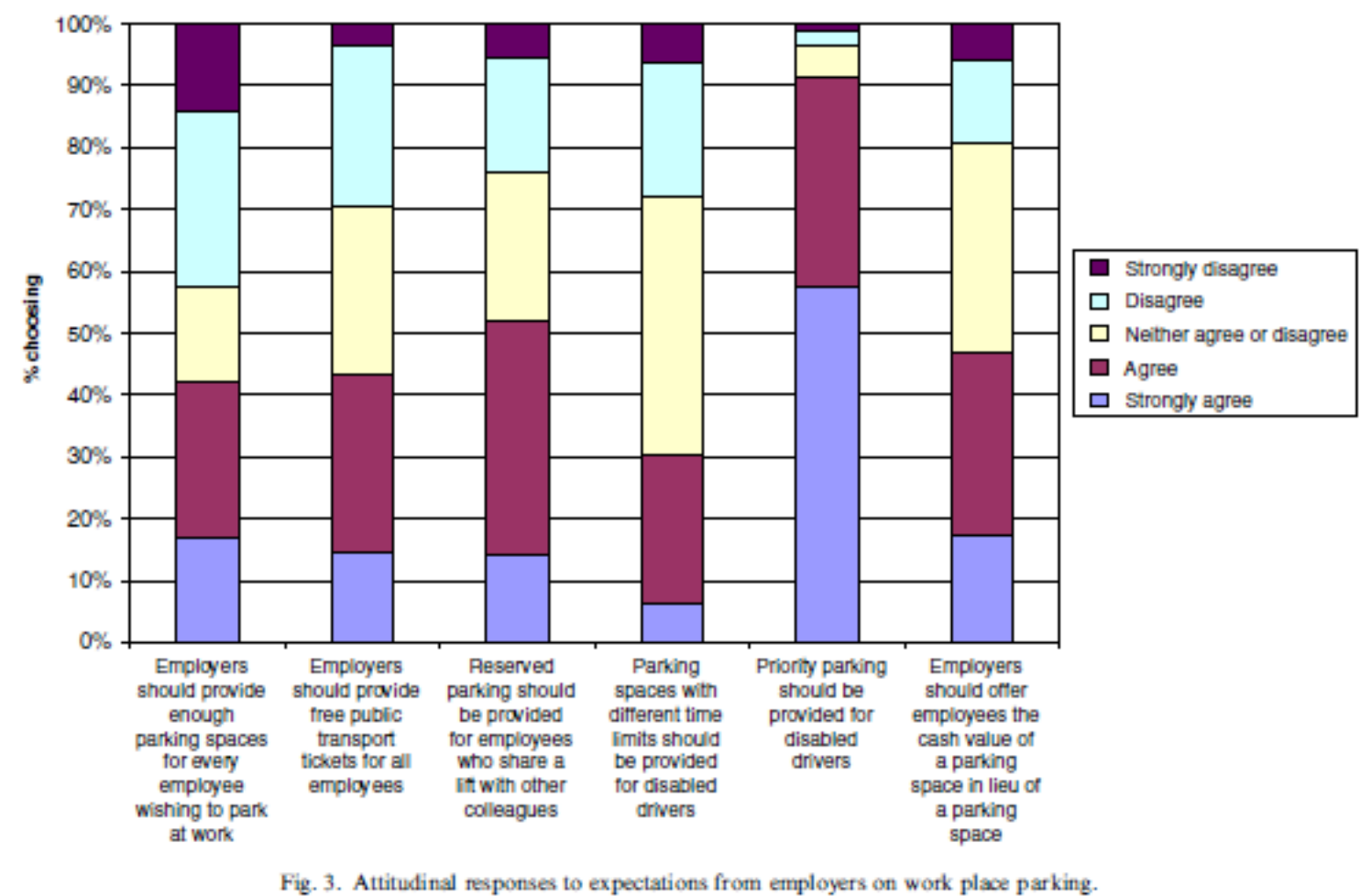

\subsection{Attitudinal responses to parking at work place issues}

Respondents were asked to indicate the level of importance they attached to a series of parking related factors, the results of which are presented in Fig. 2. With 'very important' and 'important' rates combined, the security of vehicles was deemed as the most important factor followed closely by personal safety. This finding is the same as that published by Farrell and O'Mahony (2005) on a university based sample. Walking distance from the car park to the work place and having a designated parking space had the highest ratings of 'not important' and 'not at all important', as can be seen in Fig. 2. One further attitudinal question was asked of the respondents, again focusing on what employees expect or prefer their employers to provide, the results of which are presented in Fig. 3. Only 42\% either strongly/agreed that employers should provide enough parking spaces for anyone wishing to park at work. Forty four per cent either strongly/agreed that employers should provide all employees with a free public-transport ticket for the journey to work. Forty-seven per cent agreed (or strongly agreed) that employers should offer employees the cash value of a parking space in lieu of a parking space.

\section{Discussion and conclusions}

The research is innovative in that 'cash out' policies do not currently exist in Ireland. Therefore, the research examines an innovative policy using an innovative technique: a web-based survey. Looking at the results of the behavioural responses to the h5/day charge to park at work, a relatively large group of individuals $(31.5 \%)$ would still travel to work by car. It was clear from a number of responses 
that this was quite a determined reaction and may be heavily influenced by a primary defensive reaction to the removal of something that individuals perceive to be a right. However, assuming that this may have been the reason for responding negatively for some, a sensitivity analysis to the level of the charge would be an important part of a future work programme on this topic.

Policy decisions relating to work place parking in Dublin, in part, reside with Dublin City Council, the local authority, and with employers who own or rent the spaces. Congestion charging is unlikely to be introduced in the near future and therefore other methods of demand management, such as work place parking charges, may come on to the agenda, although this is not the case at present. If this happened, it is expected that employers would only respond to a city-wide policy administered in a controlled way.

The 'cash out' strategy examined in the research presented here was a new concept for most of the participants. This coupled with the fact that changes to work place parking policy can incite significant resistance, as shown in previous work (Farrell and O'Mahony, 2005) and the fact that the answers are stated preference responses, need to be taken into consideration when reviewing the results. It would be important to estimate the error generated in the results of this research due to the survey instrument type by conducting a trial in a number of employer locations.

It can be noted from the results that the policy of cash outs might only influence part of the population. About $30 \%$ gave a high preference to giving up their space for a year and receiving a payment in lieu. This particular result was higher than the authors expected. On the basis of this result, even allowing for the possibility of the halo effect, the authors consider that the result is sufficiently positive to suggest that 'cash outs', as part of an integrated package of demand management measures, could deliver a reduction in car use.

Further work would require that (1) the survey be conducted at a number of other employer locations in the city (2) an employer run a 'cash out' scheme so that revealed preferences could be compared with the stated preference results from this work and (3) public consultation be conducted by a transport agency in Dublin to educate the public on these measures in a way that presents them as giving positive benefits to the city.

\section{Acknowledgements}

This research was funded by the PRTLI programme of the National Development Plan, administered by the Higher Education Authority. The authors would like to thank Seona Farrell for her contribution in the early stages of the project.

\section{References}

Banister, D., Berechman, J., 2000. Transport Investment and Economic Development. UCL Press, London. Central Statistics Office, 2000. QNHS, Travel to Work 1st Quarter. [online] Available from: www.cso.ie/publications/labour/qnhs2.pdf [Accessed: 5th February 2004]. 
Central Statistics Office, 2003a. Statistical Yearbook of Ireland 2003 [online] Available from: http://www.cso.ie/principalstats/yearbook2003.html [Accessed: 24th May 2004].

Central Statistics Office, 2003b. Census 2002 Principal Demographic Statistics. Stationery Office, Dublin, Ireland.

Central Statistics Office, 2003c. Information Society Statistics-Ireland. Stationery Office, Dublin, Ireland.

Dillman, D.A., Tortora, R.D., Bowker, D.K., 1998. Principles for constructing web surveys: an initial statement. Technical Report 98-50, Social and Economic Sciences Research Centre, Washington State University, Pullman, WA.

Dublin City Business Association, 2002. Survey of Car Parking in Dublin City Centre: Shoppers Cars-Vital To City Center Economy [online] Available from: http://www.dcba.ie/publications/city_news.cfm?id=77 [Accessed: 5th May 2004].

Enoch, M., 2002. UK parking cash out experience, and lessons from California. Traffic Engineering and Control, 184-187.

Farrell, S., O’Mahony, M., 2005. Attitudes and behavioural responses to measures to deal with work place parking: a case study in Dublin, Ireland. In: Proceedings of the 84th Annual Meeting of the Transportation Research Board, Washington, DC.

Gerrard, B., Still, B., Jopson, A., 2001. The impact of road pricing and workplace parking levies on the urban economy; results from a survey of business attitudes. Environment and Planning A 33, 1985-2002.

Gordon, A., 2002. Product review: surveymonkey.com-web-based survey and evaluation system http://www.surveymonkey.com. The internet and higher education, vol. 5, Issue 1, 1st Quarter 2002, pp. 83-87.

Hayslett, M.M., Wildemuth, B.M., 2004. Pixels or pencils? The relative effectiveness of Web-based versus paper surveys. Library \& Information Science Research 26 (1), 73-93.

Hess, D.B., 2001. Effect of free parking on commuter mode choice: evidence from travel diary data. Transportation Research Record 1753, 35-42.

Ison, S.G., Wall, S., 2000. An efficient transport system to support a competitive economy: the role of workplace parking charges. In: Lloyd-Reason, L., Walls, D. (Eds.), Dimensions of Competitiveness: Issues and Policies. Edward Elgar, Cheltenham, Gloucestershire, pp. 294-317.

Joinson, A.N., Reips, U.D., 2005. Personalised salutation, power of sender and response rates to web-based surveys. Computers in Human Behaviour, in press. 
Klassen, R.D., Jacobs, J., 2001. Methodological note: experimental comparison of web, electronic and mail survey technologies in operations management. Journal of Operations Management 19, 713-728.

Link, H., et al., 2000. Empirical studies on price acceptability. Project PATS, funded by the European Commission, 4th Framework Transport RTD. Deliverable 3.

Louviere, J.J., Hensher, D.A., Swait, J.D., 2005. Stated Choice Methods, Analysis and Application. Cambridge University Press, Cambridge.

Magee, C.G., Straight, R.L., Schwartz, L., 2001. Conducting web-based surveys: keys to success. The Public Manager, 47-50.

Merriman, D., 1998. How many parking spaces does it take to create one additional transit passenger? Regional Science and Urban Economics 28, 565-584.

MVA Ltd., and WS Atkins Ltd., 1999. Options for Influencing Private Non-Residential Parking Usage, Report prepared for Department of the Environment, Transport and the Regions. ROCOL, 2000. Road Charging Options for London a Technical Assessment. The Stationery Office, London.

Shoup, D.C., 1997a. Evaluating the effects of cashing out employer-paid parking: eight case studies. Transport Policy 4, 201-216.

Shoup, D.C., 1997b. The high cost of free parking. Journal of Planning Education and Research $17,3-20$.

Shoup, D.C., 2002. Buying Time at the Curb, Chapter 4 in The Half-Life of Policy Rationales: How New Technology Affects Old Issues. New York University Press (pp. 60-85).

Shoup, D., Willson, R., 1992. Commuting, congestion, and pollution: the employer-paid parking connection. Papers Presented at the Congestion Pricing Symposium, US Department of Transportation, June 10-12, pp. 7-1-7-21.

Simpson, B., 2001. Assessing the feasibility of workplace parking charges and congestion charging. Aston University Conference, Birmingham, UK, 25 April 2001.

United States Environmental Protection Agency (USEPA), 2001. Parking cash out: implementing commuter benefits under the commuter choice leadership initiative. Air and Radiation Transport and Air Quality, EPA 420-S-01-006.

Van der Mede, P., Visser, J., 1999. Effects of parking measures on traffic congestion. In: de Ortu' zar, J.D. (Ed.), Stated Preference Modelling Techniques. Perspectives 4, PTRC Education and Research Services Ltd., London, pp. 243-257. 
Van Vuren, T., Johnson, P., 2000. Assessing Possible Impacts of Workplace Charging and Investments on Traffic Levels in the West Midlands, presented at the European Transport Conference, Seminar on Transport Modelling, Cambridge, England.

Wang, T., Sharples, J., 1999. Workplace parking levy. TRL Report 399, Crowthorne.

Willson, R.W., 1992. Estimating the travel and parking demand effects of employer-paid parking. Regional Science and Urban Economics 22(1), 133-145.

Wright, R., 2005. Researching internet-based populations: advantages and disadvantages of online survey research, online questionnaire authoring software packages, and web survey services. Journal of Computer- Mediated Communication 10 (3) (article 11). 